\title{
Effects of naloxone on circulating gonadotrophin concentrations in prepubertal heifers
}

\author{
A. C. O. Evans, W. D. Currie* and N. C. Rawlings \\ Veterinary Physiological Sciences, Western College of Veterinary Medicine, University of \\ Saskatchewan, Saskatoon, Saskatchewan, S7N OWO, Canada
}

\begin{abstract}
Summary. The pattern and opioidergic control of the secretion of gonadotrophins in prepubertal heifer calves were examined. Ten age-matched Hereford heifer calves were weighed and a blood sample was taken every 2 weeks from 2 to 25 weeks of age and then weekly until 60 weeks of age. At 60 weeks, a fertile bull was introduced and at 75 weeks of age pregnancy diagnosis was performed by transrectal ultrasonography. At 4 , $12,18,24$ and 32 weeks of age, the opioid antagonist naloxone was injected (i.v., $n=5$; $1 \mathrm{mg} \mathrm{kg}^{-1}$ body weight) each hour for $12 \mathrm{~h}$. Control heifers received sterile saline at the same ages. Blood samples were collected every $12 \mathrm{~min}$ for the $12 \mathrm{~h}$ treatment and serum samples were analysed for luteinizing hormone $(\mathrm{LH})$ and follicle-stimulating hormone (FSH). Samples taken once every 2 weeks from 2 to 60 weeks were analysed for LH, FSH and oestradiol, and weekly samples were taken for progesterone determination. There was no effect of naloxone on the age at puberty, which was $56.2 \pm 0.7$ weeks at a body weight of $388.5 \pm 8.0 \mathrm{~kg}$. The mean age at conception was $63.4 \pm 0.5$ weeks. On the basis of samples taken every other week, serum concentrations of $\mathrm{LH}$ were high at 10 weeks and between 40 and 60 weeks of age. From the periods of intensive blood collection, the early rise in mean serum concentrations of $\mathrm{LH}$ appeared later at 12 and 18 weeks of age and was caused by a rise in LH pulse amplitude. Serum FSH concentrations were increased between 20 and 22 weeks and oestradiol concentrations at 22 , 56 and 58 weeks of age. At 4 weeks, naloxone increased mean LH concentrations, pulse amplitude and pulse frequency $(P<0.01)$ and thereafter only decreased LH pulse amplitude at 18 weeks $(P<0.05)$ and increased LH pulse frequency at 24 weeks $(P<0.05)$. The FSH secretion was pulsatile at all ages and naloxone only increased FSH pulse amplitude at 4 weeks.

From these data we conclude that (i) there is an early transient increase in gonadotrophin secretion in prepubertal heifers, (ii) significant opioidergic inhibition of gonadotrophin secretion occurs only in very young heifers and (iii) a decrease in endogenous opioid inhibition of LH secretion, particularly LH pulse amplitude, allows for the early rise in $\mathrm{LH}$ secretion.
\end{abstract}

Keywords: puberty; gonadotrophins; naloxone; heifer

\section{Introduction}

The mechanisms controlling the temporal pattern of circulating concentrations of gonadotrophins in prepubertal heifer calves are unknown. It appears that the pituitary and gonads in such calves can function at a very early age, since the pituitary is responsive to exogenous gonadotrophinreleasing hormone (GnRH) (Barnes et al., 1980) and fertile ovulations can be induced in very 
young heifers using exogenous gonadotrophins (Onuman et al., 1970; Seidel et al., 1971). Early hypothalamic inactivity may prevent gonadotrophic drive to the ovaries, before the increase that precedes sexual maturation (Dyer et al., 1990). Some authors suggest that there is an early rise in luteinizing hormone (LH) and follicle-stimulating hormone (FSH) at about 20 weeks of age (Schams et al., 1981); another report suggests that plasma LH concentrations decrease from birth to 15 weeks of age, and thereafter increase to 39 weeks and that FSH follows a similar pattern (Dodson et al., 1988). In bull calves, we have observed an early transient rise in gonadotrophin secretion (Rawlings et al., 1978).

There is convincing evidence that opioids play a role in regulating gonadotrophin secretion during the prepubertal period in rats (Wilkinson \& Bhanot, 1982; Bhanot \& Wilkinson, 1983). The results are not consistent between reports, but there is general agreement that there are sexual differences, and that opioids play a much greater role in female than in male rats (Schulz et al., 1982; Bhanot \& Wilkinson, 1983; Cicero et al., 1986). Puberty has been induced in female rats by the administration of the opioid antagonist naloxone, and on the basis of this it was suggested that the removal of an inhibitory opioid 'brake' triggers the onset of puberty in female rats (Sirinathsinghji et al., 1985). Studies on the role of opioids in sexual maturation in farm animals have been mainly confined to ewe lambs and have also produced inconsistencies (Haynes et al., 1989; Rawlings \& Churchill, 1990). In our data (Rawlings \& Churchill, 1990), little opioidergic suppression of LH secretion was seen in ewe lambs until the last 10 weeks before first oestrus; in the study of Haynes et al. (1989), no opioidergic effect was seen until the ewes were sexually mature. Opioid receptors have been measured in fetal and newborn lambs and adult ewes; the concentrations increase through fetal life reaching concentrations in the newborn that are higher than those found in adults (Villiger et al., 1982).

The present experiment investigated whether an early transient increase in circulating concentrations of gonadotrophins occurs in prepubertal heifers and studied the role of endogenous opioids in regulating the early onset and changes in gonadotrophin secretion.

\title{
Materials and Methods
}

\begin{abstract}
Animals
Ten age-matched ( \pm 5 days) Hereford heifer calves were maintained in a beef management system; calves were nursed at pasture until weaning at 21 weeks of age and then maintained in a paddock and fed a ration of $21 \%$ ground barley, $51 \%$ ground hay, $22 \%$ ground straw and $0.005 \%$ of a $1: 1$ calcium phosphorus mineral mix (w/w) ad libitum, with brome and lucerne hay and water also freely available. Each calf was weighed and a single blood sample drawn by jugular venepuncture every two weeks from 2 to 25 weeks of age; then samples were taken once a week until 60 weeks of age. At 60 weeks of age, a fertile bull was introduced and at 75 weeks of age pregnancy diagnosis was performed by transrectal ultrasonography and conceptus age was estimated.
\end{abstract}

\section{Naloxone treatments}

The calves received hourly intravenous bolus injections of naloxone in saline $\left(n=5: 1 \mathrm{mg} \mathrm{kg}^{-1}\right.$ body weight h${ }^{-1}$; Research Biomedicals Inc., Natick, MA, USA) or physiological saline solution $(n=5)$ for 12 h at $4,12,18,24$ and 32 weeks of age. On the day before treatment, the calves were fitted with indwelling jugular vinyl tubing catheters (SV-70; i.d. $1.0 \mathrm{~mm}$, o.d. $1.5 \mathrm{~mm}$; Dural Plastics and Engineering, Dural, NSW, Australia). Throughout the $12 \mathrm{~h}$ infusion period, $4 \mathrm{ml}$ blood samples were drawn every $12 \mathrm{~min}$. Cows were housed in stalls indoors overnight, with their calves loose and free to nurse, before the day of blood sampling. Weaned calves were cannulated in a similar way and housed unrestrained overnight.

\section{Blood handling and radioimmunoassays}

All blood samples were allowed to clot at room temperature for $12-18 \mathrm{~h}$; the clots were removed and, after centrifuging at $1500 \mathrm{~g}$ for $20 \mathrm{~min}$, the serum was poured off and stored at $-20^{\circ} \mathrm{C}$ until analysis. Weekly blood samples were collected from the heifers in sodium heparinized vacutainers and spun within $20 \mathrm{~min}$ of collection; the plasma was aspirated and stored at $-20^{\circ} \mathrm{C}$ until analysis. 
LH, FSH and progesterone. Concentrations of LH, FSH and progesterone in serum were all determined in doubleantibody radioimmunoassays using iodinated tracers (Rawlings et al., 1984). LH concentrations are expressed in terms of NIDDK-bLH4. The range of the standard curve was from 0.06 to $8 \mathrm{ng} \mathrm{ml}^{-1}$. The sensitivity of the assay was $0 \cdot 1 \mathrm{ng} \mathrm{ml}^{-1}$; this was the lowest concentration of unlabelled LH that could displace iodinated LH from the first antibody $(P<0.05$ by $t$ test). Intra- and interassay coefficients of variation (CVs) were 12.3 and $18.7 \%$, respectively, (mean $=2.90 \mathrm{ng} \mathrm{ml}^{-1}$ serum) and 11.2 and $18.6 \%$ (mean $=0.71 \mathrm{ng} \mathrm{ml}^{-1}$ serum). For the FSH assay the first antibody used was NIDDK-anti-oFSH-1, and FSH concentrations are expressed in terms of USDA-bFSH-I1. The range of the standard curve was $0.13-16 \mathrm{ng} \mathrm{ml}^{-1}$. The sensitivity of the assay was $0.2 \mathrm{ng} \mathrm{ml}^{-1}(P<0.05)$. Intraand interassay CVs were 9.1 and $14.0 \%$, respectively, (mean $=3.10 \mathrm{ng} \mathrm{ml}^{-1}$ serum) and 9.1 and $16.7 \%$ (mean $=1.69 \mathrm{ng} \mathrm{ml}^{-1}$ serum). The range of the progesterone standard curve was $0.1-10 \mathrm{ng} \mathrm{ml}^{-1}$; the sensitivity of the assay was $0.1 \mathrm{ng}$ progesterone $\mathrm{ml}^{-1}$ of plasma. Intra- and interassay CVs were 5.1 and $15.5 \%$ (mean $=5 \cdot 19 \mathrm{ng} \mathrm{ml}^{-1}$ plasma) and 4.5 and $15 \cdot 8$ (mean $=2 \cdot 16 \mathrm{ng} \mathrm{ml}^{-1}$ plasma).

Oestradiol. Oestradiol was measured by radioimmunoassay (Joseph et al., 1992). The range of the standard curve was $1-100 \mathrm{pg} \mathrm{ml}^{-1}$ and the assay sensitivity was $1 \mathrm{pg}$ oestradiol $\mathrm{ml}^{-1}$ serum. The intra- and interassay CVs were $9 \cdot 4$ and $11 \%\left(\right.$ mean $=18.1 \mathrm{pg} \mathrm{ml}^{-1}$ serum) and 15 and $22 \%$ (mean $6.9 \mathrm{pg} \mathrm{ml}^{-1}$ serum).

\section{Statistical analysis}

The episodic secretion of LH and FSH during the $12 \mathrm{~h}$ intensive bleeds were determined using PC-Pulsar (J. Gitzen \& V. Ramirez, University of Illinois, USA). Tonic LH and FSH secretion is expressed in terms of basal and mean circulating concentrations, pulse amplitude and pulse frequency for the $12 \mathrm{~h}$ periods of intensive blood sampling. Episodes were identified using standard deviation criteria (Meriam \& Wachter, 1982) and basal concentrations were determined by subtraction of episodes from the profile.

Comparison of the LH and FSH data from the intensive bleeds between control and naloxone-treated heifers at each age was performed by repeated measures ANOVA on the Statistical Analysis System (SAS, Version 6). StudentNewman-Keuls test for least-significant difference $(P<0.05)$ was used as the postanova test. The annual profiles for mean serum concentrations of FSH, LH and oestradiol were analysed using repeated measures ANOVA (True Epistat, Epistat Services, Richardson, Texas, USA) and Student-Newman-Keuls $(P<0.05$ and $P<0.01)$ was used to determine age effects on the secretion of these hormones. The annual profiles for mean serum concentrations of LH, FSH and oestradiol were also blocked into 6-week periods and the analysis was repeated.

\section{Results}

The mean ( \pm SEM) birthweight was $40 \cdot 3 \pm 1 \cdot 4 \mathrm{~kg}$ and the average growth rate between birth and 56 weeks was $0.97 \pm 0.10 \mathrm{~kg} \mathrm{day}^{-1}$. The onset of puberty was taken to be the first age at which progesterone concentrations exceeded $0.4 \mathrm{ng} \mathrm{ml}^{-1}$ of plasma and was $56.2 \pm 0.7$ weeks at a body weight of $388.5 \pm 8.0 \mathrm{~kg}$. Five of the ten animals showed concentrations of progesterone $>0.25 \mathrm{ng} \mathrm{mi}^{-1}$ plasma for 1 to 2 weeks immediately before the onset of puberty. The mean age at conception was $63 \cdot 4 \pm 0.5$ weeks.

Statistical analysis across all data points (Fig. 1) showed a significant effect of time $(P<0.001)$ in the FSH and oestradiol profiles, but not for the LH profile $(P=0.09)$. FSH concentrations at 20 and 22 weeks of age were different $(P<0.05)$ from $70 \%$ of all other points and the oestradiol concentration at 22 weeks was significantly greater $(P<0.05)$ than the nadirs at 2 and 38 weeks, but less than $(P<0.05)$ the concentrations at 56 and 58 weeks of age. When blocked into 6-week periods, a significant effect of time $(P<0.001)$ was noted in the annual profiles of LH, FSH and oestradiol. LH concentrations between 8 and 14 weeks of age were higher than those at 2 to 8 weeks of age $(P<0.01)$ and 14 to 36 weeks of age. LH concentrations from 38 to 60 weeks of age were higher $(P<0.05)$ than between 14 and 36 weeks. When the FSH data were blocked into 6-week periods, FSH concentrations between 18 and 24 weeks were higher than those at all other ages $(P<0.01)$.

Examination of the 12-h LH profiles for control heifers across ages showed that mean circulating concentrations of $\mathrm{LH}$ and $\mathrm{LH}$ pulse amplitude were higher $(P<0.05)$ at 12 and 18 weeks of age than at 4, 24 and 32 weeks of age (Fig. 2). There were no differences in FSH secretory patterns among ages $(P>0.05)$ (Fig. 3). At 4 weeks of age, the naloxone treatment resulted in an increase in mean LH concentrations $(P<0.05)$, LH and FSH pulse amplitude $(P<0.01)$ and LH pulse frequency $(P<0.01)$ (Fig. 4). Thereafter, naloxone administration decreased only LH pulse amplitude at 18 weeks $(P<0.05)$ and increased LH pulse frequency at 24 weeks of age $(P<0.05)$. 


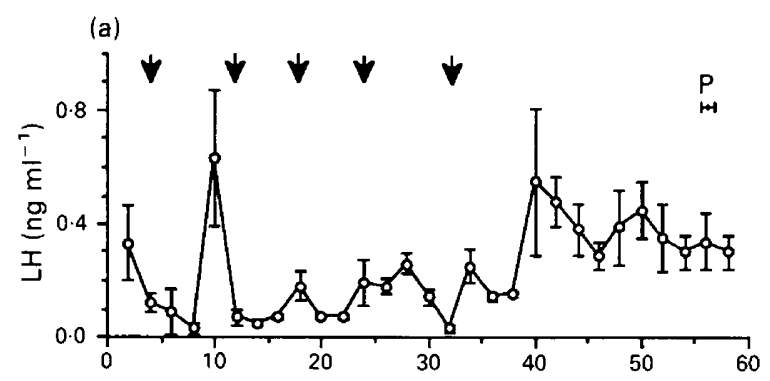

(b)
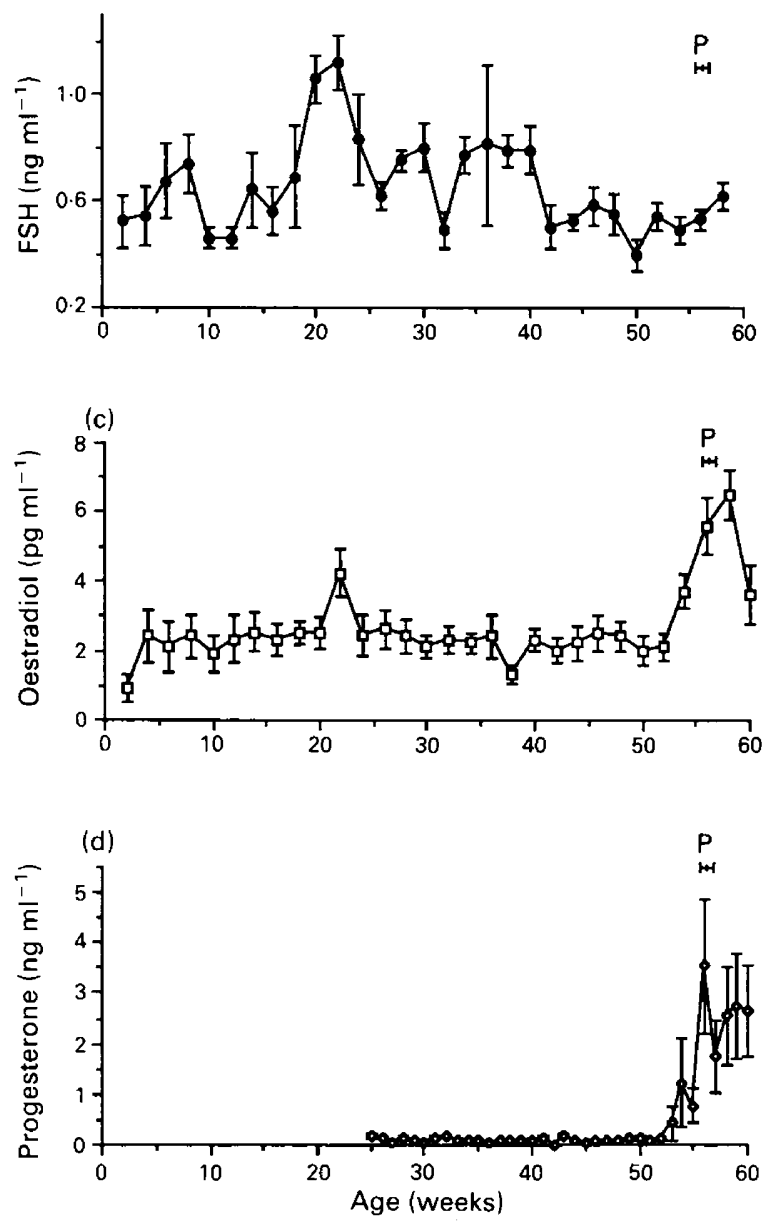

Fig. 1. Mean ( \pm SEM) concentrations of (a) luteinizing hormone (LH), (b) follicle-stimulating hormone (FSH), (c) oestradiol and (d) progesterone for Hereford heifers from 2 to 60 weeks of age $(n=10) . \mathrm{P}=$ puberty at $56 \cdot 2 \pm 0.7$ weeks. Arrows indicate the ages at which intensive bleeds were performed.

\section{Discussion}

Available data suggest that the pituitary and ovaries of prepubertal heifers are functional before oestrous cycles are initiated, since pituitary responses to GnRH have been reported (Barnes et al., 

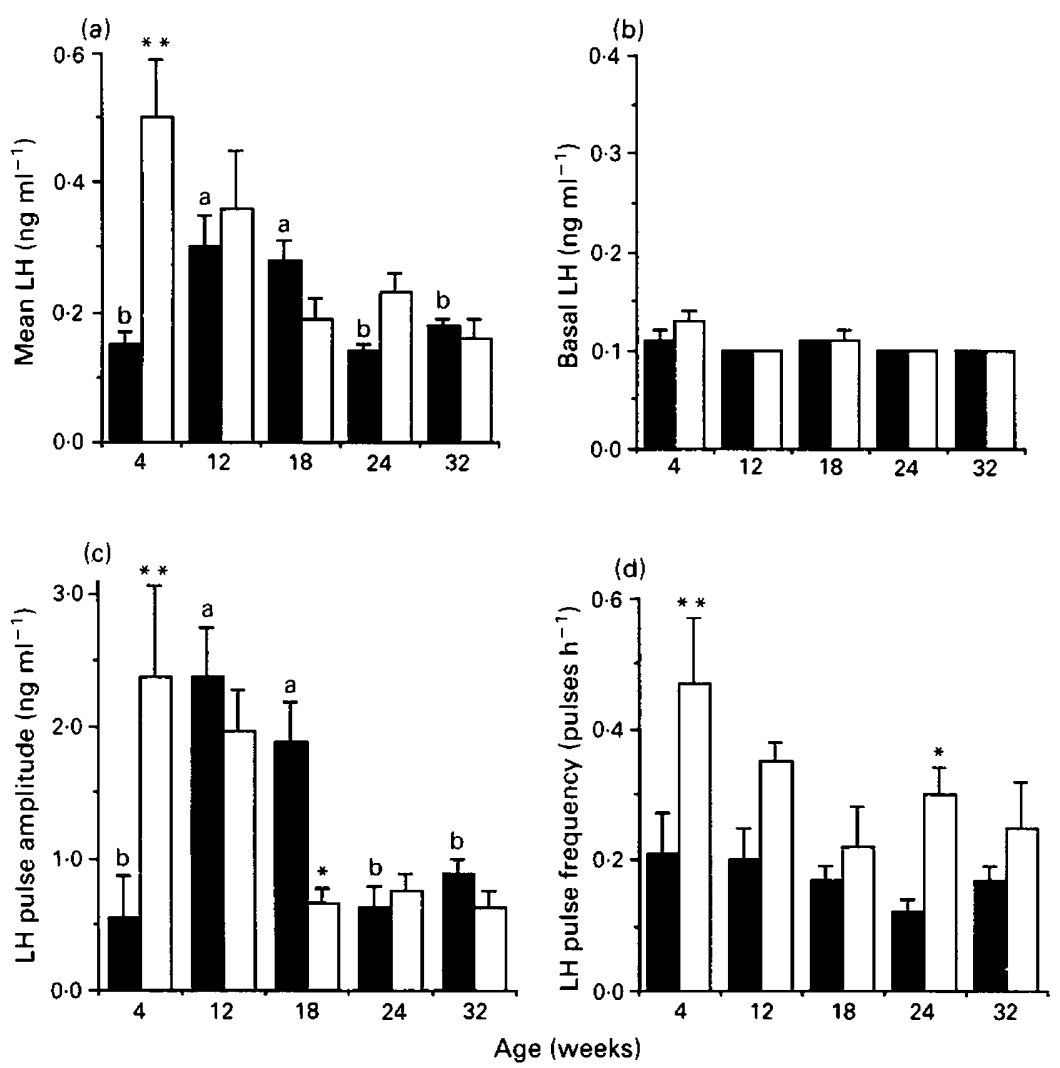

Fig. 2. Mean (a) and basal (b) luteinizing hormone ( $\mathrm{LH}$ ) concentrations and LH pulse amplitude (c) and frequency (d) (mean \pm SEM) in heifers treated with naloxone ( $\square, n=5$; $1 \mathrm{mg} \mathrm{kg}^{-1}$ body weight $\left.\mathrm{h}^{-1}\right)$ or saline $(\mathbf{E}, n=5)$ for $12 \mathrm{~h}$ at $4,12,18,24$ and 32 weeks of age; blood samples were taken every $12 \mathrm{~min}$. Significant differences between treatment and control groups at an age are shown by $* P<0.05$ and ${ }^{* *} P<0.01$. Control groups with different superscripts are significantly different $(P<0.05)$.

1980) and exogenous gonadotrophins can cause superovulatory responses in 4- and 8-week-old calves (Seidel et al., 1971). Schams et al. (1981) describe prepubertal basal concentrations of gonadotrophins as exhibiting a biphasic profile, a rise and fall in $\mathrm{LH}$ and FSH occurring between birth and 20 weeks of age. However, Dodson et al. (1988) considered that serum LH and FSH concentrations decreased from birth to 15 and 19 weeks, respectively, and then increased to 39 weeks of age. Our data (Fig. 1) showed circulating LH concentrations to be high at 10 weeks of age, based on blood samples taken once every 2 weeks. An intensive bleed was not conducted at this time, but the intensive bleeds at 12 and 18 weeks showed an increase in mean LH concentrations as a result of an increase in $\mathrm{LH}$ pulse amplitude (Fig. 2). The reason that this is not evident in the annual profile is probably because of the inaccuracies involved in determining the concentrations of a pulsatile hormone based on single samples, particularly when very high-amplitude but lowfrequency pulses are involved. In addition, the stress of obtaining single samples may have reduced LH secretion at this time by interfering with GnRH secretion (Rivier \& Rivest, 1991). We have observed these kinds of discrepancies between LH patterns in blood samples collected weekly and during intensive sampling previously (Rawlings et al., 1978). However, despite the variance in the data due to high-amplitude pulses, we consider that there is a short-lived early rise in mean circulating LH concentrations in heifer calves detected at 10 weeks in blood samples taken once every 2 weeks, but more accurately at 12 and 18 weeks by intensive sampling. 

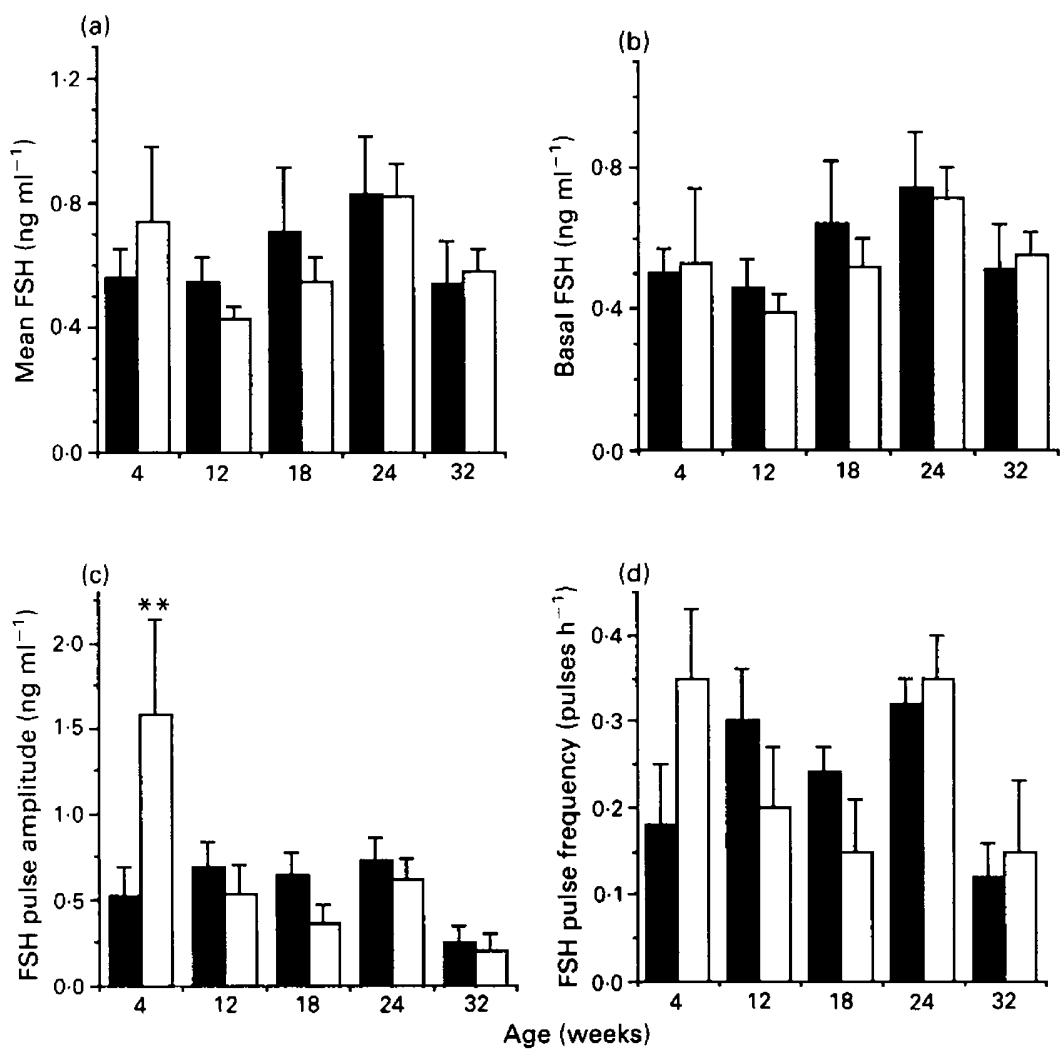

Fig. 3. Mean (a) and basal (b) follicle-stimulating hormone (FSH) concentrations and FSH pulse amplitude (c) and frequency (d) (mean \pm SEM) in heifers treated with naloxone $(\square, n=5$; $1 \mathrm{mg} \mathrm{kg}^{-1}$ body weight $\left.\mathrm{h}^{-1}\right)$ or saline $(\boldsymbol{\square}, n=5)$ for $12 \mathrm{~h}$ at $4,12,18,24$ and 32 weeks of age; blood samples were taken every $12 \mathrm{~min} .{ }^{* *}$ Significant difference between treatment and control groups $(P<0 \cdot 01)$.

Mean circulating concentrations of FSH also showed an early increase at about 22 weeks of age, based on single samples taken once in 2 weeks (Fig. 1). The intensive sampling periods did not occur during this rise, but sampling was done on the increase at 18 weeks and the decrease at 24 weeks of age. Mean FSH concentrations, determined during intensive bleedings, are slightly higher at these ages than at other ages (Fig. 3). The consistency in mean FSH data between samples collected once every 2 weeks and intensively collected blood samples compared with the LH data may be due to a higher pulse frequency in FSH than in LH profiles. The increase in FSH probably caused an increase in follicular activity resulting in the increase in oestradiol seen at 22 weeks of age (Fig. 1).

A short-lived early increase in LH and FSH secretion may aid ovarian development, as has been suggested for LH and normal testicular growth in bull calves (McCarthy et al., 1979; Amann \& Walker, 1983). Desjardins \& Hafs (1969) conducted a study of follicle populations at slaughter in Holstein heifers and found that numbers of small $(<5 \mathrm{~mm})$ and large $(>5 \mathrm{~mm})$ ovarian follicles increased from birth to a maximum at 16 weeks of age, then decreased to 24 weeks of age and remained fairly constant until 1 year old. Prolonged exposure to high concentrations of gonadotrophins could have deleterious effects on the early developing ovary in the form of unwanted ovulations or cystic structures. Hence, a high sensitivity to the negative feedback effects of FSHstimulated oestradiol may reduce the early rise in circulating concentrations of gonadotrophins at this age. It has been shown that, as puberty draws closer, there is a decline in oestradiol negative feedback on $\mathrm{LH}$ secretion and that this may be mediated by a decrease in oestradiol receptors at the 

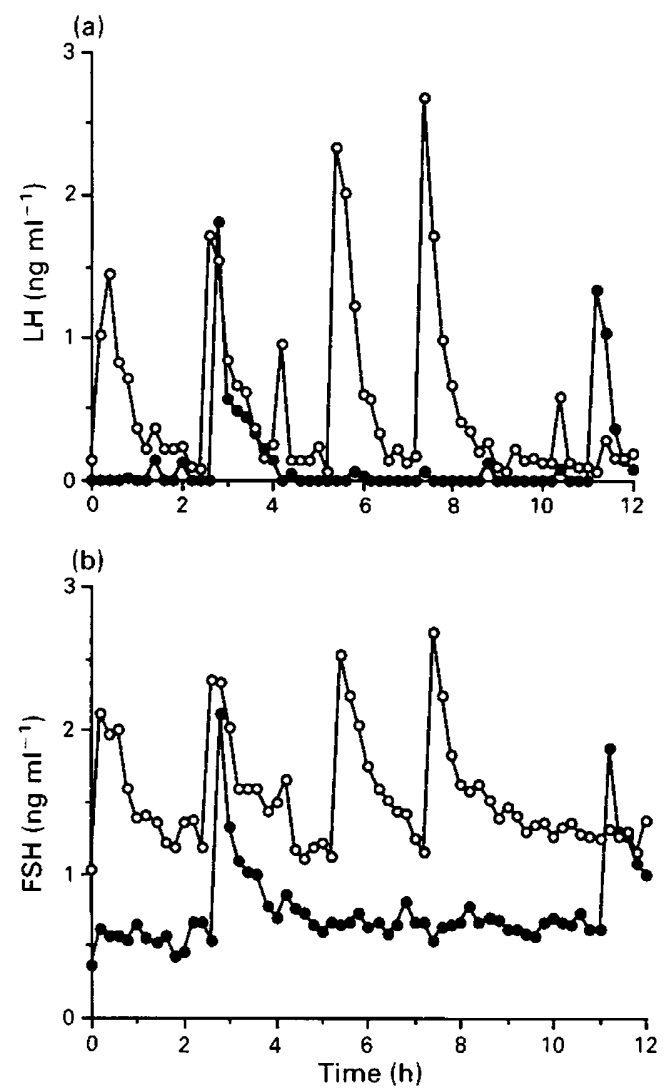

Fig. 4. Temporal pattern of serum concentrations of (a) luteinizing hormone (LH) and (b) follicle-stimulating hormone (FSH) in blood samples collected every $12 \mathrm{~min}$ for $12 \mathrm{~h}$ from two representative heifers at 4 weeks of age. Heifers were treated with saline $(O)$ or naloxone $(O$; $1 \mathrm{mg} \mathrm{kg}^{-1}$ body weight $\mathrm{h}^{-1}$ ).

hypothalamus and pituitary (Day et al., 1987). We consider that the early rise in LH and FSH, causing a transient rise in follicular activity, is an important event and suggest that this is a major component in the initiation and organization of cyclic ovarian activity, which persists throughout reproductive life.

The results presented here show that in 4-week-old heifer calves there is strong opioid inhibition of mean circulating $\mathrm{LH}$ concentrations, $\mathrm{LH}$ pulse amplitude and $\mathrm{LH}$ pulse frequency as demonstrated by its reversal with naloxone $(P<0 \cdot 01)$. The higher LH pulse amplitude seen in control animals at 12 and 18 weeks than in controls at other ages $(P<0.05)$ is likely to be the reason for the increase seen in mean LH concentrations $(P<0.05)$. Since no effects of naloxone were seen during this time (except for the anomalous decrease in $\mathrm{LH}$ pulse amplitude at 18 weeks), and as naloxone had strong effects at 4 weeks of age in increasing $\mathrm{LH}$ secretion, it would appear that the removal of opioidergic inhibition between 4 and 12 weeks of age allowed for the increase in LH secretion seen in the control animals. Apart from an increase in LH pulse frequency at 24 weeks, no evidence of opioidergic suppression of LH secretion was noted after 18 weeks of age. It therefore appears that, in the immediate postnatal period, there was opioidergic suppression of $\mathrm{LH}$ secretion, but that this effect diminished after 4 weeks of age and was minimal up to at least 32 weeks of age. It has been suggested that in rats diminished opioidergic suppression of $\mathrm{LH}$ secretion may be involved in the initiation of ovarian cyclicity (Sirinathsinghii et al., 1985); this was not apparent in studies of ewe lambs (Haynes et al., 1989; Rawlings \& Churchill, 1990). Haynes et al. (1989) reported that 
prepubertal heifers treated monthly with an opioid antagonist, WIN-3, showed enhanced LH secretion every month from 6 to 12 months of age.

Circulating patterns of FSH in heifer calves were pulsatile at all the ages studied. However, opioidergic inhibition of FSH secretion was demonstrated only at 4 weeks of age in the form of enhanced pulse amplitude $(P<0.01)$. Hence, opioidergic control of FSH secretion occurs to a small extent at 4 weeks of age and is not demonstrable thereafter until at least 32 weeks of age. This is in agreement with studies in sheep, where there does not appear to be opioid involvement in the control of FSH secretion in adult ewes (Currie \& Rawlings, 1989) or ewe lambs (Rawlings \& Churchill, 1990).

Opioids control the pattern of gonadotrophin secretion to different extents at different ages in heifer calves. The mechanism of opioidergic regulation is unknown, but two possibilities must be considered. First, opioidergic systems may act in concert with, or relay information from, higher centres in the brain which control reproduction; second, opioids may partially or wholly mediate feedback of agents of systemic origin (e.g. steroids from the gonads) on the GnRH-producing areas of the hypothalamus or both of these actions may occur (Kalra, 1985). Deaver \& Peters (1988) conducted a study on the changes in prepubertal hypothalamic metabolism of amines in bull calves and related these to changes in LH secretion. They concluded that the hypothalamic mechanisms regulating the secretion of $\mathrm{LH}$ are not fully functional until 12 weeks of age. Is the neonatal hypothalamus therefore dysfunctional or is its activity depressed? The results of this study tend to suggest that opioidergic mechanisms suppress an otherwise functional postnatal hypothalamus in heifer calves. Later on in the prepubertal period, opioidergic control of gonadotrophin secretion alters, possibly reflecting changes in the role of feedback agents of gonadal origin or maturational modifications in the organization of hypothalamic structures. A possible explanation for this is that opioids are involved in gonadotrophin suppression during the early postnatal period, but that, soon after, strong negative feedback by oestradiol, working through routes not involving opioids, overrides any opioidergic control mechanisms. Then, just before puberty, the role for opioids reappears to 'fine tune' LH secretion during subsequent oestrous cycles (Haynes et al., 1989). A study with ovariectomized oestradiol-implanted ewe lambs suggested that this was not the case, as opioidergic suppression of $\mathrm{LH}$ secretion was reversed with naloxone, despite high oestradiol concentrations (Ebling et al., 1989), which possibly reflects a species difference. It would appear that opioids are involved in the early organization of $\mathrm{LH}$, and perhaps $\mathrm{FSH}$, secretion in heifer calves, and that they resume some regulatory significance in the later stages of sexual maturation.

We have demonstrated that, in heifer calves 10-22 weeks old, there is an increase in circulating gonadotrophin concentrations, which stimulates follicular activity. Opioidergic control of gonadotrophin secretion occurs in 4-week-old calves, but thereafter is much reduced or absent. A decrease in endogenous opioid inhibition appears to allow for the early transient rise in LH secretion.

The authors thank S. J. Cook for technical assistance, W. M. Kerr and his staff for care and management of the animals and NIDDK and USDA for the provision of purified hormones. This research was funded by the National Sciences and Engineering Research Council of Canada.

\section{References}

Amann, R.P. \& Walker, O.A. (1983) Changes in the pituitary-gonadal axis associated with puberty in Holstein bulls. Journal of Animal Science 57, 433-442.

Barnes, M.A., Bierley, S.T., Halmark, R.D. \& Henricks, D.M. (1980) Follicle stimulating hormone, luteinizing hormone and estradiol-17 $\beta$ response in GnRHtreated prepubertal Holstein heifers. Biology of Reproduction 22, 459-465.
Bhanot, R. \& Wilkinson, M. (1983) Opioidergic control of gonadotropin secretion during puberty in the rat: a neurochemical basis for the hypothalamic 'gonadostat'. Endocrinology 113, 596-603.

Cicero, T.J., Schmoeker, P.F., Meyer, E.D., Miller, B.T., Bell, R.D., Cytron, S.M. \& Brown, C.C. (1986) Ontogeny of the opioid-mediated control of reproductive endocrinology in the female rat. Journal of Pharmacology and Experimental Therapeutics 236, 627-633. 
Currie, W.D. \& Rawlings, N.C. (1989) Fluctuations in responsiveness of $\mathrm{LH}$ and lack of responsiveness of FSH to prolonged infusion of morphine and naloxone in the ewe. Journal of Reproduction and Fertility 86, 359-366.

Day, M.L., Imakawa, K., Wolf, P.L., Kittok, R.J. \& Kinder, J.E. (1987) Endocrine mechanisms of puberty in heifers: role of hypothalamo-pituitary estradiol receptors in the negative feedback of estradiol on luteinizing hormone secretion. Biology of Reproduction 37, 1054-1065.

Deaver, D.R. \& Peters, J.L. (1988) Age related changes in secretion of luteinizing hormone and metabolism of hypothalamic amines in bull calves prior to puberty. Biology of Reproduction 39, 622-629.

Desjardins, C. \& Hafs, H.D. (1969) Maturation of bovine female genitalia from birth through puberty. Journal of Animal Science 28, 502-507.

Dodson, S.E., McLeod, B.J., Haresign, W., Peters, A.R. \& Lamming, G.E. (1988) Endocrine changes from birth to puberty in the heifer. Journal of Reproduction and Fertility 82, 527-538.

Dyer, R.M., Bishop, M.D. \& Day, M.L. (1990) Exogenous estradiol reduces inhibition of luteinizing hormone by estradiol in prepubertal heifers. Biology of Reproduction 42, 755-761.

Ebling, F.J.P., Schwartz, M.L. \& Foster, D.L. (1989) Endogenous opioid regulation of pulsatile luteinizing hormone secretion during sexual maturation in the female sheep. Endocrinology 125, 369-383.

Haynes, N.B., Lamming, G.E., Yang, K-P., Brooks, A.N. \& Finnie, A.D. (1989) Endogenous opioid peptides and farm animal reproduction. Oxford Reviews of Reproductive Biology 11, 111-145.

Joseph, I.B.J.K., Currie, W.D. \& Rawlings, N.C. (1992) Effects of time after ovariectomy, season and oestradiol on luteinizing hormone and folliclestimulating hormone secretion in ovariectomized ewes. Journal of Reproduction and Fertility 94, $511-523$.

Kalra, S.P. (1985) Neural circuits involved in the control of LHRH secretion: a model for estrous cycle regulation. Journal of Steroid Biochemistry 23, 733-742.

McCarthy, M.S., Hafs, H.D. \& Convey, E.M. (1979) Serum hormone patterns associated with growth and sexual development in bulls. Journal of Animal Science 49, 1012-1020.
Merriam, G.R. \& Wachter, K.W. (1982) Algorithms for the study of episodic hormone secretion. American Journal of Physiology 243, E310-E318.

Onuman, H., Hahn, J. \& Foote, J.H. (1970) Factors affecting superovulation, fertilization and recovery of superovulated ova in prepubertal cattle. Journal of Reproduction and Fertility 21, 119-126.

Rawlings, N.C. \& Churchill, I.J. (1990) Effect of naloxone on gonadotrophin secretion at various stages of development in the ewe lamb. Journal of Reproduction and Fertility 89, 503-509.

Rawlings, N.C., Fletcher, P.W., Henricks, D.M. \& Hill, J.R. (1978) Plasma luteinising hormone (LH) and testosterone levels during sexual maturation in beef bull calves. Biology of Reproduction 19, 1108-1112.

Rawlings, N.C., Jeffcoate, I.A. \& Reiger, D.L. (1984) The influence of estradiol-17及 and progesterone on peripheral serum concentrations of luteinizing hormone and follicle stimulating hormone in the ovariectomized ewe. Theriogenology 22, 473-488.

Rivier, C. \& Rivest, S. (1991) Effects of stress on the activity of the hypothalamic-pituitary-gonadal axis: peripheral and central mechanisms. Biology of Reproduction 45, 523-532.

Schams, D., Schallenberger, E., Gome, S. \& Karg, H. (1981) Endocrine patterns associated with puberty in male and female cattle. Journal of Reproduction and Fertility Supplement 30, 103-110.

Schulz, R., Wilhelm, A., Pirke, K.M. \& Herz, A. (1982) Regulation of luteinizing hormone secretion in prepubertal male and female rats. Life Sciences 31, 2167-2170.

Seidel, G.E., Larson, L.L. \& Foote, R.H. (1971) Effects of age and gonadotropin treatment on superovulation in the calf. Journal of Animal Science 33, 617-622.

Sirinathsinghji, D.J.S., Motta, M. \& Martini, L. (1985) Induction of precocious puberty in the female rat after chronic naloxone administration during the neonatal period; the opiate 'brake' on puberty gonadotropin secretion. Journal of Endocrinology 104, 299-307.

Villiger, J.W., Taylor, K.M. \& Gluckman, P.D. (1982) Ontogenesis of opiate receptors in regions of the ovine brain. Pediatric Pharmacology 2, 349-356.

Wilkinson, M. \& Bhanot, R. (1982) A puberty related attenuation of opiate-induced inhibition of $\mathrm{LH}$ secretion. Endocrinology 110, 1046-1048.

Received 19 December 1991 